\title{
How Should Pediatricians in India Address Behavior Patterns Associated With Childhood Obesity?
}

\author{
JONATHAN WeLLS \\ Professor of Anthropology and Pediatric Nutrition, Childhood Nutrition Research Centre, UCL Institute of Child Health, 30 \\ Guilford Street, London WC1N 1EH, UK.j.wells@ich.ucl.ac.uk
}

$\mathrm{T}$ he nutritional transition is well underway in India, reflected both in rapid economic development, and in an epidemic of type 2 diabetes and cardiovascular disease [1]. Rapid increases in children's adiposity, referred to by Kuriyan and colleagues [2] in their article published in this issue of Indian Pediatrics, indicate powerful exposure of the youngest age groups to these winds of change.

The study of several thousand children makes several important contributions to understanding why children's waist girths are increasing [2]. Various behaviors were implicated, with one thing in common: they all relate to 'modernity' - new foods in the Indian diet, new ways of eating, new leisure habits such as TV viewing. These behaviors are not brand new; rather they are recently arrived and spreading across the population in a way that can be likened to a 'cultural virus.' Even the parental contribution to children's adiposity identified by the authors may involve more than genotype. Transgenerational effects may involve non-genetic impacts of parental lifestyle (eg: diet during pregnancy) on the next generation [3].

The discipline of medicine consolidated in the late $19^{\text {th }}$ century under the influence of germ theory, to deal with biological pathogens. The aims were clear: diagnose the illness, identify the disease agent, and find its weak point so as to eliminate exposure, decrease transmission, or treat the symptoms. Given adequate funding, medicine does this very effectively. Rates of infectious disease today arguably track financial indicators much more strongly than local ecological conditions. Social factors also make a major contribution to health through living conditions, acting through physiological mechanisms such as diet, or exposure to pollution or physical injury. Again, financial indicators are fundamental, malnutrition goes hand in hand with poverty, and economic development is seemingly a panacea for all these ills.

And so it is; albeit with a profound cost. Economic development does indeed enable progress in specific public health arenas, and many middleincome countries have seen an impressive reduction in rates of childhood malnutrition and infectious disease [4]. But as nutrition 'improves', why do people get fatter rather than taller?

The current mode of economic development brings with it a whole range of new disease vectors, and the medical community is still struggling to understand and adjust. Indeed the 'dual burden' - the simultaneous presence of both undernutrition and overnutrition in communities, even within families makes it seemingly impossible to address both at the same time.

These new disease vectors are very different to those familiar to clinicians. They spread at the speed of TV transmission rather than on the wings of the mosquito, they can infect entire schools or neighborhoods with a few well-targeted billboards, and they co-opt their human hosts into passive submission through clever marketing practices. Despite frequent reference to 'market choice', modern capitalism makes its profits primarily by making people's choices for them [5], and so-called 
'emerging market' countries such as India are increasingly where those profits are being made.

How should clinicians, and especially pediatricians, respond? The experience of western countries is not encouraging. Governments are unwilling to regulate adequately the commercial interests that substantially boost their tax revenues. But with tens of millions of diabetics in India already, you can't afford to copy our dismal inertia.

The food industrial complex is arguably currently more dangerous to human health than any single biological pathogen. When I was last in India, in November, I visited a new supermarket to review the kinds of foods being sold in such outlets. The shelves were stacked with sweets, biscuits, readymade foods and sugary drinks. The individual products may not all be new, and I confess to personal past experience with several Indian brands of soft drinks. But in this kind of supermarket, it is impossible to escape sugar. It is in almost every product, sweet or savory. Evidence increasingly suggests that sugar (sucrose) is more harmful to health than fat, due to its profound effects on insulin metabolism [6,7]. And sugar has long been one the fastest and most lucrative routes to profit on planet earth, hence its locus at the heart of economic development worldwide.

It would be easy to assume that the disease vectors of modernization are therefore foods, perhaps in particular those containing sugar. This would be a mistake, like identifying Plasmodium as the cause of malaria but missing the role of the mosquito. The real disease vectors are the strategies and power that characterize the food and leisure industries [5] that make it increasingly difficult for the majority of people to avoid unhealthy foods and lifestyles. The obesogenic behaviors identified by Kuriyan and colleagues are being powerfully shaped by these commercial interests.

I believe that pediatricians need to treat the food industrial complex like a disease, a deadly disease, if you are to have any chance of success in tackling the Indian diabetes epidemic. You'll need different skills to those conventional in the clinic or laboratory. And it may be uncomfortable and challenging. Corporate strategy is likely to be an unpleasant sight when analyzed under the microscope. You need to ask some very tough questions. And here is one for starters. Why were some of the biscuits in that supermarket, containing $72.3 \mathrm{~g}$ carbohydrate per $100 \mathrm{~g}$, including $27.3 \mathrm{~g}$ sugar, marketed by the same company that in 2005 entered the Indian diabetes therapeutic arena with the launch of two drugs, Windia and Windamet?

Competing interests: None stated.

Funding: None.

\section{REFERENCES}

1. Misra A, Khurana L. The metabolic syndrome in South Asians: epidemiology, determinants, and prevention. Metab Syndr Relat Disord. 2009;7:497-514.

2. Kuriyan R, Thomas T, Sumithra S, Lokesh DP, Sheth NR, Joy R, et al. Potential factors related to waist circumference in urban south Indian children. Indian Pediatr. 2011;48:765-770.

3. Wells JC. The thrifty phenotype as an adaptive maternal effect. Biol Rev Camb Philos Soc. 2007;82:143-72.

4. Uauy R, Kain J. The epidemiological transition: need to incorporate obesity prevention into nutrition programmes. Public Health Nutr. 2002;5:223-9.

5. Baudrillard J. The Consumer Society: Myths and Structures. Los Angeles: Sage Publications; 1970/1998.

6. Lustig RH. The 'skinny' on childhood obesity: how our western environment starves kids' brains. Pediatr Ann. 2006;35:898-907.

7. Taubes G. The Diet Delusion. London: Vermillion; 2008. 